\title{
Electron Skirts and X-ray Correction: Evaluating Methods for Rapid Discrimination of Primary versus Secondary X-ray signals in the ESEM
}

\author{
Eric Doehne
}

The Getty Conservation Institute, 1200 Getty Center Drive, Suite 700, Los Angeles, CA 90049

For EDS "spot" analyses in the ESEM, data presented here show that two subtraction methods using internal standards can provide a useful indication of what elements are truly present in the sample under the primary beam and what portion of the signal is actually part of the ancillary X-ray spectrum produced by gas-scattered electrons.

The increasing popularity of ESEM, VP-SEM, and LV-SEM instruments has raised interest in ways to differentiate or unmix these two X-ray signals generated in these instruments. Under conditions of high gas pressure or long gas path length, a significant fraction of the electrons that make up the primary beam are scattered after colliding with gas molecules as the beam passes through the higherpressure region above the sample. These electrons form a broad, flat skirt that surrounds the primary beam $[1,2]$. Previous experiments have documented the shape of the skirt and its effect on the X-ray resolution $[3,4]$.

Efforts to establish quantitative correction methods for EDS microanalysis to account for the effect of skirt X-ray events have been successful [5-7], but somewhat cumbersome and time-consuming. A more popular approach for spot analyses has been to minimize skirt formation through the use of lower gas pressures and shorter gas path lengths where possible and the invention of extended detectors optimized for ESEM/EDS, which move the vacuum closer to the sample [8,9]. Nevertheless, there are situations where a significant X-ray skirt component is present, for example, in instruments with a normally long gas path length (VPSEM and LVSEM) and in the microanalysis of hydrated materials (ESEM). For qualitative analysis, often what is required is a rapid indication of what elements in the "mixed" spectra are truly under the primary beam and what part of the overall spectra is coming from the skirt.

Data presented here evaluate the effectiveness of simple subtraction methods to unmix the spectra. Two approaches were tested: one where the beam is fixed and the pressure is varied. The two spectra are subtracted to obtain a skirt spectrum. The skirt spectrum can then be used to evaluate the "purity" of the initial, mixed spectrum. The second method is one where the beam is rapidly scanned over the skirt area to acquire a simulated skirt spectrum which is then subtracted from a "spot spectrum" to produce a "skirt" spectrum. Each method has been proposed [10,11], but additional testing is needed to verify the limits and speed of the methods. We also suggest the use of an internal standard in the skirt area to act as a guide to the degree of subtraction required and an evaluation of the time required to determine if an element is truly in the skirt or under the beam (Figs. $1 \& 2$ ). Any element that is only present in the skirt area will function as an internal standard. Copper tape works well in this case.

\section{References}

[1] D.A. Moncrieff, P.R. Barker, and V.N.E. Robinson, J. Phys. D: Appl. Phys., 1979. 12: p. 481488. 
[2] G.D. Danilatos, Advances in Electronics and Electron Physics, 1988. 71: p. 109-250.

[3] E. Doehne and N. Bower, Microbeam Analysis, 1993. 2(supplement): p. S35-36.

[4] B.J. Griffin, R.L. Trautman, and J. Coffey. MAS'93: Microbeam Analysis Society 27th Annual Meeting and AEM. 1993. Los Angeles, CA (USA).

[5] E. Doehne, Scanning, 1997. 19(2): p. 75-78.

[6] R. Gauvin, Scanning, 1999. 21(6): p. 388-393.

[7] J.B. Bilde-Sørensen, Microscopy Today. 1998. p. 10.

[8] N.W. Bower, D.C. Stulik, and E. Doehne, Fresenius Journal Analytical Chemistry, 1994. 348(56): p. 402-410.

[9] T. Rice. 2002. Personal Communication.

[10] R.B. Bolon. Microbeam Analysis 1991, the 25th Annual Conference of the Microbeam Analysis Society. 1991. San Jose, CA: San Francisco Press, Inc., Box 6800, San Francisco, CA 94142-6800. USA 1991.

[11] E. Doehne, Scanning, 1996. 18(3): p. 164-165.

[12] Acknowledgements: The support of Giacomo Chiari and David Carson in this research is gratefully acknowledged. Stimulating discussions with colleagues Robert Carlton and Brendan Griffin have helped to further develop the ideas presented here.

FIG 1. EDS Spectra showing A) original mixed spectrum showing $\mathrm{Cu}$ (internal standard) and complex aluminosilicate B) subtraction to produce "skirt" spectrum containing $\mathrm{Cu}$ and $\mathrm{K}$ not present in area under the primary beam C) final corrected spectrum with pressure change method [5].
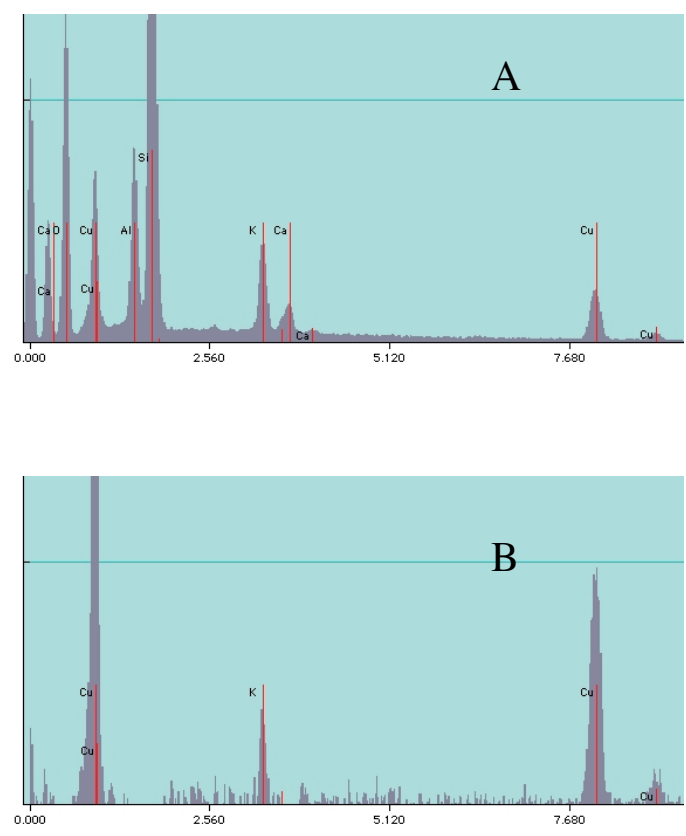

Fig 2. Backscattered electron image of volcanic tuff showing several phases. For qualitative spot analysis an internal $\mathrm{Cu}$ standard is used to control the degree of empirical correction required. $320 \mu \mathrm{m}$ width.
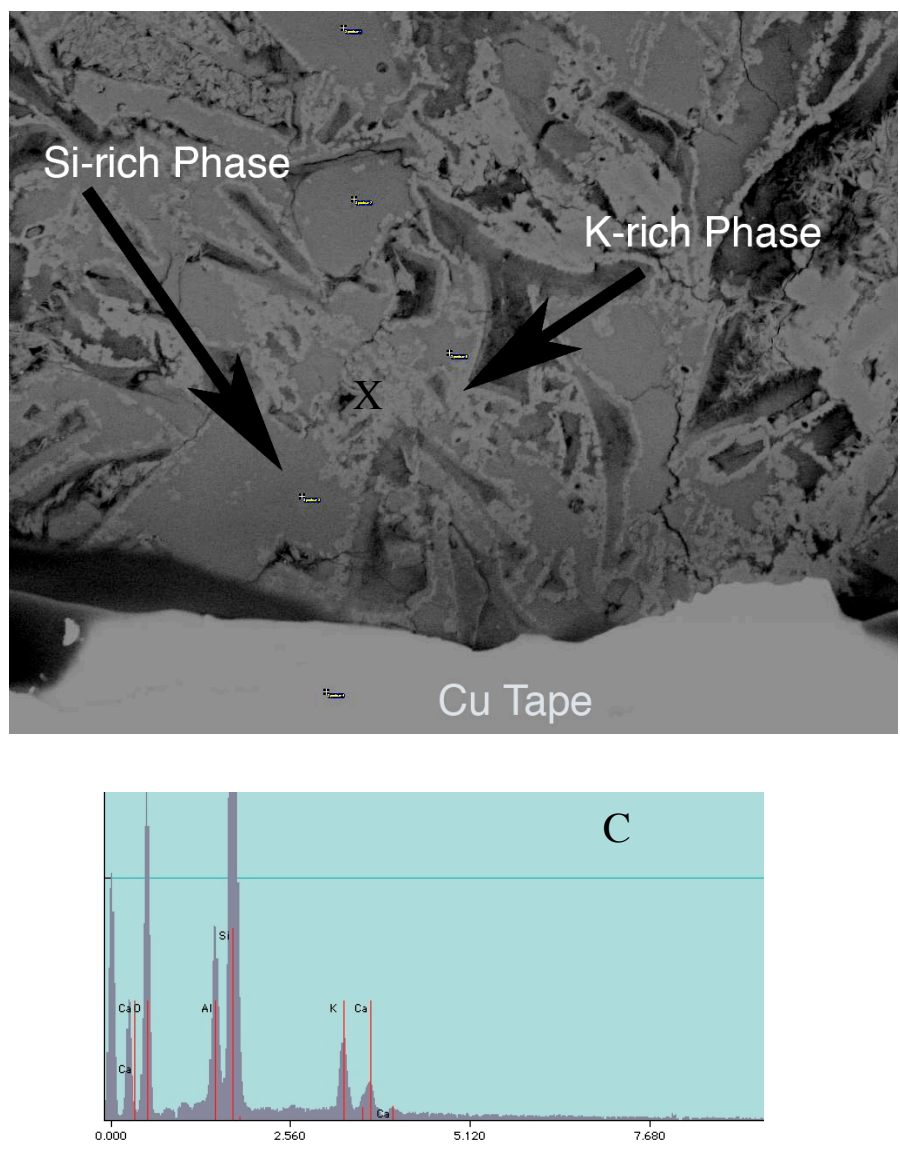